\title{
Dynamics of attentional bias for food in adults, children, and restrained eaters
}

Citation for published version (APA):

Liu, Y., Roefs, A., Werthmann, J., \& Nederkoorn, C. (2019). Dynamics of attentional bias for food in adults, children, and restrained eaters. Appetite, 135, 86-92. https://doi.org/10.1016/j.appet.2019.01.004

Document status and date:

Published: 01/04/2019

DOI:

10.1016/j.appet.2019.01.004

Document Version:

Publisher's PDF, also known as Version of record

Document license:

Taverne

Please check the document version of this publication:

- A submitted manuscript is the version of the article upon submission and before peer-review. There can be important differences between the submitted version and the official published version of record.

People interested in the research are advised to contact the author for the final version of the publication, or visit the DOI to the publisher's website.

- The final author version and the galley proof are versions of the publication after peer review.

- The final published version features the final layout of the paper including the volume, issue and page numbers.

Link to publication

\footnotetext{
General rights rights.

- You may freely distribute the URL identifying the publication in the public portal. please follow below link for the End User Agreement:

www.umlib.nl/taverne-license

Take down policy

If you believe that this document breaches copyright please contact us at:

repository@maastrichtuniversity.nl

providing details and we will investigate your claim.
}

Copyright and moral rights for the publications made accessible in the public portal are retained by the authors and/or other copyright owners and it is a condition of accessing publications that users recognise and abide by the legal requirements associated with these

- Users may download and print one copy of any publication from the public portal for the purpose of private study or research.

- You may not further distribute the material or use it for any profit-making activity or commercial gain

If the publication is distributed under the terms of Article $25 \mathrm{fa}$ of the Dutch Copyright Act, indicated by the "Taverne" license above, 


\title{
Dynamics of attentional bias for food in adults, children, and restrained eaters $^{\text {मे }}$
}

\author{
Yu Liu ${ }^{\mathrm{a}, *}$, Anne Roefs ${ }^{\mathrm{a}}$, Jessica Werthmann ${ }^{\mathrm{b}}$, Chantal Nederkoorn ${ }^{\mathrm{a}}$ \\ ${ }^{a}$ Department of Clinical Psychological Science, Faculty of Psychology and Neuroscience, Maastricht University, Maastricht, the Netherlands \\ ${ }^{\mathrm{b}}$ Department of Clinical Psychology and Psychotherapy, Institute of Psychology, Albert-Ludwigs University of Freiburg, Freiburg, Germany
}

\section{A R T I C L E I N F O}

\section{Keywords:}

Attentional bias

Dynamics

Executive control

Obese

Restrained eaters

\begin{abstract}
A B S T R A C T
Objective: Empirical evidence of attentional bias $(\mathrm{AB})$ for food in obese and restrained eaters is contradictory. It has been suggested that $\mathrm{AB}$ for food in obese people might reflect both food craving and food-related concerns. Thus, AB for food may be a dynamic process.

Methods: A new computational methodology (Zvielli, Bernstein, \& Koster, 2015) was adopted to reanalyze the reaction time (RT) and dwell time of three food-related dot-probe task with eye-tracking studies (Werthmann et al., 2015; Werthmann et al., 2011, 2013). This new computing method uses a sequence of bias scores to express the dynamic changes of $\mathrm{AB}$. Moreover, the variability of RT on filler trials was also calculated. The critical groups in these studies were overweight/obese adults, obese children, and healthy-weight restrained eaters.

Results: Both the variability of $\mathrm{AB}$ for food stimuli and the variability of RT on filler could significantly predict the variance in body mass index (BMI). When controlling for the variability of RT on filler trials and mean $\mathrm{AB}$ score, larger variability of $\mathrm{AB}$ for food stimuli still existed in obese children and aggregated dataset. The variability of $\mathrm{AB}$ for food stimuli demonstrated no significant correlation with restrained eating scores and dwell time variability. Conclusions: Overweight/obese individuals are characterized by more variability in attention, and this variability is mainly unspecific. It probably reflects less effective executive control ability.
\end{abstract}

Currently, people are surrounded by high-caloric palatable foods (Lake \& Townshend, 2006) possibly attracting their attention (McSorley, Morriss, \& van Reekum, 2017). According to incentive salience model, such food-related attentional bias (AB) can subsequently result in craving for food, and it might be especially true for overweight and obese people (Berridge, Ho, Richard, \& DiFeliceantonio, 2010; Frankort et al., 2012; Roefs, Houben, \& Werthmann, 2015).

Quite some studies have examined $A B$ for food in individuals of different body weights (e.g., obese, overweight and normal-weight) by using dot-probe task which has most often been used to measure $A B$. However, empirical evidence for food-related $A B$ in overweight and obese is contradictory (e.g., Roefs et al., 2015; Werthmann, Jansen, \& Roefs, 2015). Briefly, overweight and obese participants showed more, equal or less attention for food cues, compared to lean participants (e.g., Deluchi, Costa, Friedman, Goncalves, \& Bizarro, 2017; Doolan, Breslin, Hanna, \& Gallagher, 2015; Nummenmaa, Hietanen, Calvo, \& Hyona, 2011). The reason for this inconsistency may be partly attributed to the inadequate internal reliability and retest reliability of mean attentional bias scores (Ataya et al., 2012; Schmukle, 2005). Besides, mean AB scores only provide a central tendency of $\mathrm{AB}$ but do not provide information at different time points. However, using eye tracking and ERP, two studies found an attentional approach-avoidance pattern in overweight people (Nijs, Franken, \& Muris, 2010; Werthmann et al., 2011). This approachavoidance pattern might reflect two conflicting goals: eating enjoyment and weight control (Stroebe, van Koningsbruggen, Papies, \& Aarts, 2013), possibly leading dieters to alternate between directing their attention towards and away from food. Given all that, it may be more fitting to consider $\mathrm{AB}$ for food as dynamic, reflecting the current motivational state, rather than a stable characteristic (Field et al., 2016; Werthmann, Jansen, \& Roefs, 2016). Mean AB scores may have disguised or canceled out group differences in previous studies.

Zvielli, Bernstein, and Koster (2015) have proposed a new computational methodology to capture the proposed dynamic nature of $\mathrm{AB}$ : trial level bias scores (TL-BS). TL-BS consists of a time-series of AB measured over the course of the task. More specifically, in the dot-probe task, each congruent trial is matched with an incongruent trial that is as close as possible in time, no further than five trials away (before or after) from the congruent trial. Then, the $\mathrm{AB}$ is calculated by subtracting the response time

\footnotetext{
¿ Y.L received support from Chinese Government Scholarship under China Scholarship Council (No. 201706990024).

* Corresponding author. Clinical Psychological Science (UNS40), Faculty of Psychology and Neuroscience, P.O. Box 616, 6200 MD, Maastricht, the Netherlands.

E-mail address: yu.liu@maastrichtuniversity.nl (Y. Liu).
} 
of each of the congruent trials from its paired incongruent trials, resulting in a time-series of $A B$ scores. To capture the dynamic nature of $A B$, TL-BS variability was computed as the mean absolute distance across the whole sequence of TL-BSs, which reflects the extent of fluctuation both toward and away from stimuli over time. Some research found that compared with mean AB scores, TL-BS variability better predicted symptoms in depressed and spider phobic (Zvielli et al., 2015; Zvielli, Vrijsen, Koster, \& Bernstein, 2016). In addition, those with emotion dysregulation exhibited greater TLBS variability when they were faced with threat-related pictures (Bardeen, Daniel, Hinnant, \& Orcutt, 2017). However, other researchers have critiqued the TL-BS methodology and showed that TL-BS parameters are sensitive to increasing the standard deviation $(S D)$ of reaction time (RT) in the absence of a bias (Kruijt, Field, \& Fox, 2016). According to Kruijt et al. (2016), a higher $S D$ may reflect error variance and the TL-BS parameters cannot differentiate measurement error from bias variability. So, TL-BS may capture the variability in general responding, and not in threat-related attention. It is important to distinguish whether the variability is specifically for emotion/food-related bias or a more general variability.

Given the potential benefits of the TL-BS, we used it to reanalyze the AB data of three studies (Werthmann et al., 2011, 2015, 2013). Because we want to focus on the dynamic nature of attentional bias for food, TLBS variability was chosen, as it reflects the degree of fluctuation in attention for food across time. The included studies used the dot-probe task to measure RT as well as eye-tracking variables. The studies compared obese and healthy-weight adults (Werthmann et al., 2011), overweight/obese and healthy-weight children (Werthmann et al., 2015), and high and low-restrained eaters matched on body mass index (BMI) (Werthmann et al., 2013). Whereas one of these studies did find evidence that overweight/obese adults directed their first gaze more often toward food pictures (Werthmann et al., 2011), no effect was found for the RT-based measure of AB in any of the studies.

The primary purpose was to test whether the variability of $A B$ (as measured with TL-BS) for food is associated with BMI and restrained eating scores. The second aim was to test whether the variability is specific for food stimuli or is observed on filler trials as well. So, the variability of RT on filler trials (mean $S D /$ mean RT) and mean RT on filler trials were selected to express the variability and aggregation in general responding. The third aim was to test whether the variability of $\mathrm{AB}$ for food is related to the variability of eye-tracking variable, dwell time bias, which reflects the maintenance of attention on critical stimuli (Mogg, Field, \& Bradley, 2005). So, the triallevel computing method was used again to calculate the dwell time variability. The final aim was to test whether TL-BS variability can explain more variance than mean $\mathrm{AB}$ scores and the variability of $\mathrm{RT}$ on filler trials.

For all the three studies, it was hypothesized that: (1) The variability of $\mathrm{AB}$ for food, but not the variability of RT on filler trials would significantly correlate with BMI and restrained eating scores; (2) The variability of $A B$ for food would be associated with the dwell time variability. (3) The variability of $A B$ for food would explain the variance in $\mathrm{BMI}$ and restrained eating scores on top of mean $\mathrm{AB}$ scores and the variability of RT on filler trials.

\section{Analysis 1: TL-BS in overweight/obese and healthy-weight adults}

Analysis 1 reanalyzed reaction time (RT) and gaze dwell time data in the dot-probe task administered to overweight/obese and healthyweight females (Werthmann et al., 2011). In this study, RT, eye movements, BMI, restrained eating scores, and the consumption of food were recorded. All methods are described in detail in Werthmann et al. (2011), and here a summary of the most relevant information is provided. All the studies received ethical approval.

\subsection{Method}

Participants. A total 56 participants female students (age $M=19.45, S D=1.67$; BMI $M=23.90, S D=4.35$ ) took part in this study, including 22 overweight/obese and 34 healthy-weight.

Visual Probe task. AB was measured with the dot-probe task (MacLeod, Mathews, \& Tata, 1986) while eye movements were recorded. Each trial started with a fixation cross, followed by a pair of pictures, presented side-by-side for $2000 \mathrm{~ms}$. Then, one of the stimuli was replaced by the probe (*), which randomly appeared on the left or right side of the screen, and the probe was presented until the participant pressed the response key. Participants were instructed to focus their gaze first on the fixation cross and then respond to the probe as quickly as possible. This task included incongruent trials (ITs), congruent trials (CTs) and filler trials. On ITs, the probe appeared in the location of the non-food stimulus, whereas on CTs the probe appeared in the location of the food stimuli. Filler trials included two non-food pictures, and the probe appeared in the location of one of them.

The task included 120 trials: 80 critical trials (ITs and CTs) and 40 filler trials. The critical trials consisted of 20 pairs of food and instrument stimuli and filler trials included 10 pairs of nonfood stimuli. All pairs of stimuli were each presented four times.

Taste test. A bogus taste test was conducted to measure participants' food intake, which was computed by weighing the highly palatable foods before and after the taste test.

Data reduction. The exclusion criteria of RT were the same as in Werthmann et al. (2011; 2.3\% of data were excluded). Three participants were excluded only from the analyses of consumption as they deviated more than $2 S D s$ from their group mean consumption; three participants were excluded only from the analyses of dwell time as they did not move their eyes on a sufficient proportion $(50 \%)$ of trials (The number of excluded participants is different from Werthmann et al., 2011. They excluded participants with an outlying value on any of the measured dependent variables (i.e., food consumption, eye-tracking variables, RT), whereas we only excluded participants with an outlying value when the variables were used).

The computation of attentional indexes. Mean $A B$ scores were computed by subtracting the mean RT of congruent from the mean RT of incongruent trials. For the calculation of trial-level bias scores (TL-BS), each congruent trial was matched with an incongruent trial that was as close as possible in time, no further than five trials away. For each pair, the RT or dwell time of the congruent trial was subtracted from the incongruent trial. So, a positive bias score can be interpreted as attention toward food and a negative bias score as attention away from food. TL-BS variability was computed as the sum of absolute distances between sequential TL-BSs (regarding to reaction time) on critical trials divided by the total number of TL-BSs (Zvielli et al., 2015). Similar to TL-BS variability, the calculation of dwell time variability was the sum of all absolute distances between sequential trial-by-trial dwell times divided by the total number of dwell times. The variability of RT on filler trials was the mean $S D$ on filler trials divided by the mean RT on filler trials. In our study, the mean number of IT-CT pairs was $56.07(S D=2.05$, range from 52 to 62) and the mean distance between each IT and CT was 1.93 trials $(S D=0.18$, range from 1.5 to 2.32$)$ in this study.

\subsection{Statistical analyses}

The BMI in study 1 had a unimodal distribution, so it was considered as continuous data. First, several zero-order correlations were conducted to test the associations between all attentional variables, BMI, restrained eating scores, and food consumption. Then the hierarchical linear regressions were performed to determine whether TL-BS variability could explain more variance than the variability of RT on filler trials, and mean $\mathrm{AB}$ scores for food. It was tested whether the control variables age and food consumption were related to the dependent variable (BMI), in which case they would need to be added to the model. However, age, and food consumption were not related ( $r=0.20$ and $0.11, p=.13$ and .42 ). Tests for multicollinearity indicated that a low level of multicollinearity was present (VIF $=1.04$ to 2.17 ). The independent variables were $\mathrm{z}$ transformed before entering into the statistical model. 


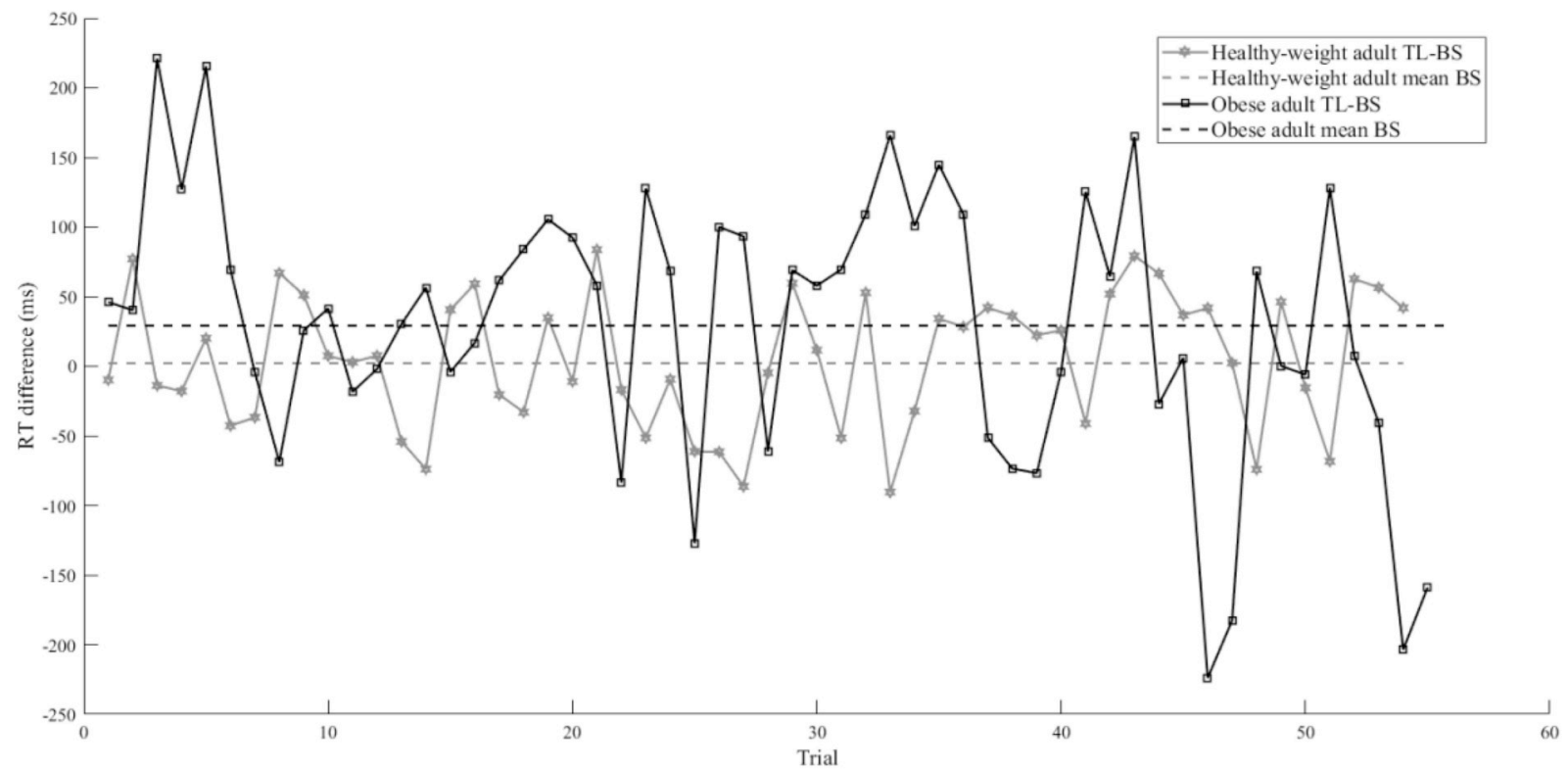

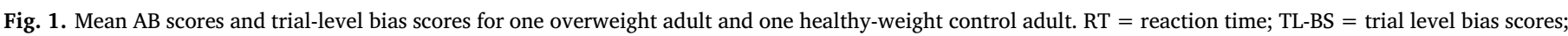
mean $\mathrm{AB}$ scores $=$ mean attentional bias scores.

\subsection{Results}

Attentional indexes, BMI, restrained eating, and consumption. An example of mean $\mathrm{AB}$ scores and trial-level bias scores of an overweight and a healthy-weight adult was showed in Fig. 1. The results of correlations demonstrated that TL-BS variability was significantly related to BMI $(r=0.27$, $p<.05)$, but not to restrained eating and consumption $(r=0.16$ and 0.02 , $p=.25$ and .89). The variability of RT on filler trials was significantly related to BMI $(r=0.29, p<.05)$, but not to restrained eating or consumption as well $(r=0.17$ and $0.02, p=.22$ and .88$)$. The other measures of attention (mean AB scores, mean RT on filler trials, and dwell time variability) were not significantly related to BMI, restrained eating and consumption ( $r=-0.24$ to $0.21, p s=.10$ to .94$)$. TL-BS variability was not significantly related to dwell time variability $(r=0.23, p=.10)$, but the two indices of variability, TL-BS variability and the variability of RT on filler trials, were significantly related to each other, $r=0.73, p<.01$.

Hierarchical regressions. The results of hierarchical linear regressions demonstrated that the model including only standardized mean $\mathrm{AB}$ scores did not significantly explain variance in BMI. Introducing the standardized variability of RT on filler trials explained an additional $7.6 \%$ of variation in BMI and this change in $R^{2}$ was significant but adding the standardized TL-BS variability did not significantly improve the model further. See Table 1 for details.

\subsection{Discussion}

In analysis 1, TL-BS, a measure of variability in attentional bias was used to reanalyze the dot-probe task data in overweight/obese and normal-weight female students (Werthmann et al., 2011). The results showed that TL-BS variability was related to BMI. However, the variability appeared not specific for food stimuli, as the variability of RT on filler trials was also related to BMI. Moreover, TL-BS variability could not explain a significant proportion of variance in BMI above the mean $\mathrm{AB}$ scores together with variability of RT on filler trials. So, this suggests that participants with higher BMI, show more fluctuations in their attention to both food and general stimuli. As TL-BS variability showed no significant relation to dwell time variability on food stimuli, it may be concluded that the fluctuations in responding are not specifically related to attention towards or away from food.

\section{Analysis 2: TL-BS in obese and healthy-weight children}

In analysis 2, reaction time (RT) and dwell time data of the dotprobe task administered to obese and healthy-weight children (Werthmann et al., 2015) were reanalyzed. In this study, RT, eye movements and adjusted BMI \% (BMI divided by the national (Dutch) norm BMI (Van Winckel \& Van Mil, 2001), adjusted for sex and age, $\times 100$.) were recorded. A summary of the most relevant information about the method is provided. See Werthmann et al. (2015) for additional details.

\subsection{Method}

Participants. 34 obese and 36 normal-weight children were recruited. After individual matching on age and sex, 30 obese (age $M=11.91, S D=2.93$; adjusted BMI \% $M=176.05, S D=23.05)$ / healthy-weight (age $M=11.82, S D=2.99$; adjusted BMI $\% M=97.49$, $S D=8.95$ ) children pairs were included in the analyses.

Visual probe task. Each trial started with a central fixation cross $(100 \mathrm{~ms})$, and subsequently, the image pair was presented $(3000 \mathrm{~ms})$. Then the probe was presented until the participant responded. The task included two blocks of 40 trials (80 trials in total): 64 critical trials and 16 filler trials. The critical trials consisted of 16 pairs of food and animal pictures and filler trials included four pairs. All pairs of pictures were presented 4 times.

Data reduction and the computation of attentional indexes. The exclusion criteria of RT were the same as in Werthmann et al. (2015; $4 \%$ of data were excluded). The calculation of mean AB scores, ${ }^{1}$ TL-BS, TL-BS variability, dwell time variability and the variability of RT on filler trials were the same as analysis 1 . The mean number of matched IT-CT pairs was $44.90(S D=2.34$, range from 39 to 50$)$ and the mean distance between each IT and CT was 1.75 trials $(S D=0.21$, range from 1.33 to 2.38 ).

\footnotetext{
${ }^{1}$ The computation method of the mean BS in analyses 2 and 3 is slightly different from Werthmann et al. (2013) and Werthmann et al. (2015), in which they divided response time into five different conditions (congruent dot left, congruent dot right, incongruent dot left, incongruent dot right and filler) and then calculated the BS.
} 
Table 1

Hierarchical regression model for variables predicting BMI.

\begin{tabular}{|c|c|c|c|c|c|c|c|c|}
\hline variables & $M(S D)$ & $B$ & $S E B$ & $\beta$ & $t$ & $F$ & $95 \% \mathrm{CI}$ & $R^{2}$ change \\
\hline Step 1 & & & & & & 0.48 & & \\
\hline Mean $\mathrm{AB}$ scores (ms) & $0.72(18.75)$ & -0.41 & 0.59 & -.09 & -0.70 & & {$[-1.59-0.77]$} & .01 \\
\hline Step 2 & & & & & & 2.47 & & \\
\hline Mean $\mathrm{AB}$ scores (ms) & & -0.25 & 0.58 & -.06 & -0.44 & & {$[-1.41-0.90]$} & \\
\hline Variability of RT on filler trials & $0.16(0.04)$ & 1.21 & 0.58 & .28 & $2.10 *$ & & {$[0.06-2.37]$} & $.08 *$ \\
\hline Step 3 & & & & & & 1.75 & & \\
\hline Mean AB scores (ms) & & -0.20 & 0.59 & -.05 & -0.34 & & {$[-1.38-0.98]$} & \\
\hline Variability of RT on filler trials & & 0.85 & 0.84 & .19 & 2.01 & & {$[-0.84-2.53]$} & \\
\hline TL-BS variability (ms) & $93.66(30.26)$ & 0.51 & 0.85 & .12 & 0.61 & & {$[-1.19-2.21]$} & .01 \\
\hline
\end{tabular}

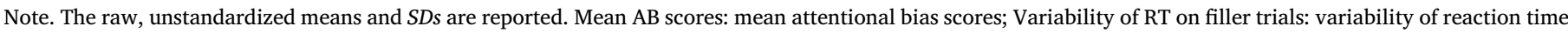

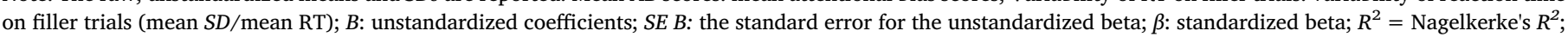
${ }^{*} p<.05$.

\subsection{Statistical analyses}

Because of the bimodal distribution of adjusted BMI, independent samples $t$-tests were conducted first to test the effect of weight-status (obese and healthy-weight) on mean AB scores, TL-BS variability, dwell time variability, mean RT on filler trials, and variability of RT on filler trials separately. Then we used binary logistic hierarchical regressions to detect whether TL-BS variability could explain additional variance above and beyond mean $\mathrm{AB}$ scores and variability of RT on filler trials. All predictors were z-standardized and they demonstrated a low level of multicollinearity, VIF $=1.02$ to 1.59 . Rank-order correlations were computed to detect whether age and sex were related to adjusted BMI. As the correlations were not significant, age and sex were not included in the regression model $(r=-0.11$ and $-0.03, p=.39$ and .80$)$.

\subsection{Results}

Attentional indexes and group status. The results of $t$-tests showed that mean $\mathrm{AB}$ scores did not significant differ between obese and healthy weight children, $t(1,58)=1.60, p=.12$. Obese children did show larger TL-BS variability than healthy-weight children, $t(1,58)=3.77, p<.01$. The variability of RT on filler trials was marginally significantly larger in the obese children than in the healthy-weight children, $t(1,58)=1.89$, $p=.06$. There was no significant difference between the weight groups in dwell time variability $t(1,58)=0.84, p=.40$, and in mean RT on the filler trials, $t(1,57)=0.67, p=.51$. TL-BS variability was significantly related to the variability of RT on filler trials $(r=0.60, p<.01)$ but not to dwell time variability $(r=-0.06, p=.64)$.

Hierarchical regressions. The results demonstrated that adding the standardized mean $\mathrm{AB}$ scores in the first step did not significantly predict weight status. The variability of RT on filler trials in the second step significantly increased the explained variance of weight-status. Finally, the standardized TL-BS variability was added in the third step, and it significantly increased the proportion of explained variance further. See Table 2 .

\subsection{Discussion}

In analysis 2, we used TL-BS to reanalyze the dot-probe task data in obese and normal-weight children. In line with our hypotheses, the results indicated that obese children demonstrated more variability of attentional bias for food (TL-BS variability) than healthy-weight children and the variability of attentional bias for food significantly predicted weight status when controlling for the variability of RT on filler trials and mean $\mathrm{AB}$ scores. Inconsistent with our hypothesis, the variability of RT on filler trials also explained more variance above mean $\mathrm{AB}$ scores. In addition, dwell time variability showed no significant association with TL-BS variability and was not different between the two weight groups. Possibly, TL-BS based on reaction time may capture different aspects of attention than those reflected in dwell time. The results of analysis 2 are partly in line with the results of analysis 1 , in that both weight groups did not differ on dwell time variability, and both overweight/obese adults and obese children showed increased variability on $\mathrm{AB}$ for food and on general reaction time. However, for obese children, specifically the variability of attentional bias for food was a better predictor of weight status than the variability of general responding.

\section{Analysis 3: TL-BS in restrained and unrestrained eaters}

Analysis 3 reanalyzed reaction time (RT) and dwell time data of dotprobe task administered to healthy-weight restrained and healthyweight unrestrained eaters (Werthmann et al., 2013). In this study, RT, eye movements, restrained eating scores, and BMI were recorded. All methods are described in detail in Werthmann et al. (2013), and a summary of the most relevant information is provided.

\subsection{Method}

Participants. 45 female participants were recruited (age $M=21.67, S D=2.05$; BMI $M=21.46, S D=1.61)$ and their restrained eating scores $(M=11.76, S D=5.50)$ were rated by Restraint Scale (Herman \& Polivy, 1980). The groups were matched on BMI.

Visual probe task. The description of the dot-probe task was the same as for analysis 1 .

Data reduction and the computation of attentional indexes. The exclusion criteria of RT were the same as in Werthmann et al. (2013; 2.3\% of data were excluded.) The calculations of all the attentional indexes were the same as analysis 1 . The mean number of matched IT-CT pairs was 56.11 $(S D=1.98$, range from 52 to 60$)$ and the mean distance between each IT and CT was 1.92 trials ( $S D=0.18$ range from 1.59 to 2.44 ) in this study.

\subsection{Statistical analyses}

The distribution of restrained eating scores was unimodal, so we first conducted zero-order correlations and then proceeded with hierarchical linear regressions, with z-standardized variables, in which we added the mean $\mathrm{AB}$ scores in the first step, the variability of RT on filler trials in the second step, and the TL-BS variability in the final step. A low level of multicollinearity was present in this study ( VIF $=1.00$ to 4.30 ). (VIF $=1.00$ to 4.30 ). The control variables age and hunger were not related to the restrained eating scores and were therefore not included in the hierarchical regressions $(r=-0.04$ and $0.12, p=.80$ and .43$)$.

\subsection{Results}

Attentional indexes and restrained eating. The restrained eating scores were not correlated significantly with TL-BS variability, mean AB scores, dwell time variability, mean RT on filler trials, and the variability of RT on filler trials ( $r=-0.23$ to $0.21, p s=.14$ to .56 ). In addition, 
Table 2

Hierarchical regression model for variables predicting weight status.

\begin{tabular}{|c|c|c|c|c|c|c|c|c|c|}
\hline \multirow[t]{2}{*}{ variable } & \multirow{2}{*}{$\begin{array}{l}\text { Obese }(n=30) \\
M(S D)\end{array}$} & \multirow{2}{*}{$\begin{array}{l}\text { Healthy-weight }(n=30) \\
M(S D)\end{array}$} & \multirow[t]{2}{*}{$B$} & \multirow[t]{2}{*}{$S E B$} & \multirow[t]{2}{*}{ Wald $\chi^{2}$} & \multirow[t]{2}{*}{$\chi^{2}$} & \multirow[t]{2}{*}{$O R$} & \multirow[t]{2}{*}{$95 \% \mathrm{CI}$} & \multirow[t]{2}{*}{$R^{2}$ change } \\
\hline & & & & & & & & & \\
\hline Step 1 & & & & & & 2.63 & & & \\
\hline Mean AB scores (ms) & $-1.19(29.01)$ & $10.25(26.29)$ & -0.45 & 0.29 & 2.37 & & 0.64 & [0.36-1.13] & .06 \\
\hline Step 2 & & & & & & $6.49^{*}$ & & & \\
\hline Mean AB scores (ms) & & & -0.47 & 0.29 & 2.66 & & 0.62 & [0.35-1.10] & \\
\hline Variability of RT on filler trials & $0.18(0.04)$ & $0.16(0.05)$ & 0.55 & 0.29 & 3.52 & & 1.73 & {$[0.98-3.10]$} & $.08^{*}$ \\
\hline Step 3 & & & & & & $17.89^{* *}$ & & & \\
\hline Mean AB scores (ms) & & & -0.70 & 0.34 & $4.28 *$ & & 0.50 & {$[0.26-0.96]$} & \\
\hline Variability of RT on filler trials & & & -0.16 & 0.39 & 0.16 & & 0.85 & {$[0.40-1.84]$} & \\
\hline TL-BS variability (ms) & $151.41(51.46)$ & $103.33(47.20)$ & 1.30 & 0.43 & $8.95^{* *}$ & & 3.66 & {$[1.56-8.56]$} & $.21 * *$ \\
\hline
\end{tabular}

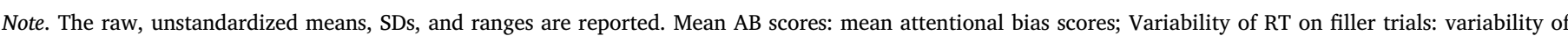

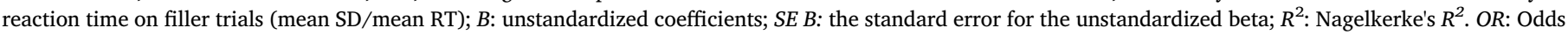
ratio, predicted probability in the obese group; ${ }^{*} p<.05 ; * * p .01$.

Table 3

Hierarchical regression model for variables predicting the restrained eating scores.

\begin{tabular}{|c|c|c|c|c|c|c|c|c|}
\hline variables & $M(S D)$ & $B$ & $S E B$ & $\beta$ & $t$ & $F$ & $95 \%$ CI & $R^{2}$ change \\
\hline Step 1 & & & & & & .23 & & \\
\hline Mean AB scores (ms) & $5.67(17.92)$ & -1.24 & 0.82 & -.23 & -1.52 & & {$[-2.89-0.41]$} & .05 \\
\hline Step 2 & & & & & & 1.64 & & \\
\hline Mean AB scores (ms) & & -1.18 & 0.82 & -.21 & -1.44 & & {$[-2.83-0.48]$} & \\
\hline Variability of RT on filler trials & $0.15(0.04)$ & -.81 & 0.82 & .15 & 0.99 & & {$[-0.85-2.46]$} & .02 \\
\hline Step 3 & & & & & & 1.32 & & \\
\hline Mean AB scores (ms) & & -1.15 & 0.82 & -.21 & -1.39 & & {$[-2.81-0.52]$} & \\
\hline Variability of RT on filler trials & & -0.45 & 1.70 & -.08 & -0.27 & & {$[-3.88-2.98]$} & \\
\hline TL-BS variability (ms) & $91.97(47.20)$ & 1.44 & 1.70 & .26 & 0.85 & & {$[-1.99-4.88]$} & .02 \\
\hline
\end{tabular}

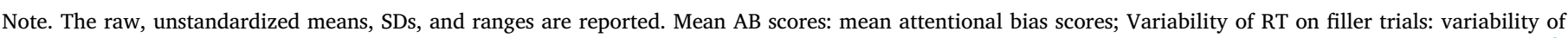

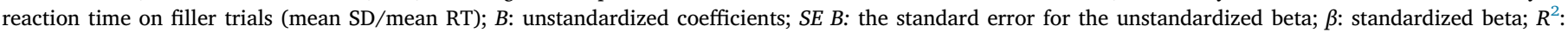
Nagelkerke's $R^{2}$.

dwell time variability did not correlate significantly with TL-BS variability $(r=0.12, p=.43$ ). However, TL-BS variability was related significantly to the variability of RT on filler trials $(r=0.88, p<.01)$.

Hierarchical regressions. Results showed that the mean $\mathrm{AB}$ scores did not significantly explain variance in restrained eating. Adding the variability of RT on filler trials and TL-BS variability did not significantly increase the proportion of explained variance in restrained eating scores. See Table 3 for details.

\subsection{Discussion}

In analysis 3, we used the TL-BS computational method to reanalyze the data in normal-weight restrained and unrestrained eaters. Different from our prediction, the results indicated that (1) TL-BS variability was not related significantly to restrained eating scores and could not explain additional variance in restrained eating as well. (2) Dwell time variability was not correlated significantly with TL-BS variability. The results suggest that there is no significantly relation between restrained eating and food-related attentional dynamics. This possibly means restrained eaters are indeed not characterized by dynamic changes in food-related $\mathrm{AB}$ or TL-BS is not an adequate way to measure this. Comparing with the results of study 1 and study 2, it seems that BMI instead of restrained eating scores is more likely associated with the variability of $\mathrm{AB}$ for food or general responding. Again, the TL-BS variability did not show any association with dwell time variability, so it is necessary to reconsider what TL-BS reflects.

\section{Meta-analysis}

As all the three studies only have modest sample sizes, lack of sufficient power might be a problem. To increase the power, we aggregated the data of three studies into one dataset. Our purposes were in line with the above studies. However, we do not have restrained eating scores in study 2 and from the results of our three studies, it seems TL-BS variability is more likely related to BMI instead of restrained eating scores, so we did not present the results including restrained eating scores here (the relevant information can be found in the supplementary).

As we calculated the percentage adjusted BMI of children according to Dutch norm BMI, to create one dataset, we calculated the adjusted BMI \% for the adults in study 1 and study 3 (supplementary data) as well as study 2 . Two outliers ( $3 S D$ above the mean) in the adjusted BMI $\%$ were replaced by the nearest adjusted BMI \% of the whole sample (see Wilcox, 2001). ${ }^{2}$ After aggregated the datasets, 161 participants (158 for dwell time variability) were included in the analysis (age $M=17.24, S D=4.83$; adjusted BMI $M=116.61, S D=32.21$ ), including 30 males and 131 females.

Because of the unimodal distribution of the adjusted BMI \%, we first conducted the correlations and then used hierarchical linear regressions with z-standardized variables. As age was related to the adjusted BMI \% $(r=-0.43, p<.01)$, age was controlled in both correlations and regressions. Tests for multicollinearity indicated a low level of multicollinearity (VIF $=1.01$ to 2.38 ).

The results of partial correlations demonstrated that TL-BS variability $(\mathrm{r}=0.31, p<.01)$, mean $\mathrm{AB}$ scores $(\mathrm{r}=-0.18, p<.05)$, dwell time variability $(\mathrm{r}=0.19, p<.05)$, and the variability of RT on filler trials $(\mathrm{r}=0.21, p<.01)$ were all significantly correlated with adjusted BMI \%. In addition, TL-BS variability was positively related to the variability of RT on filler trials $(r=0.68, p<.01)$, but not related to dwell time variability $(r=-0.01, p=.95)$. For the hierarchical

\footnotetext{
${ }^{2}$ The analyses with unchanged values or exclusion of these values showed the same patterns and would lead to the same conclusions.
} 
Table 4

Hierarchical regression model for variables predicting the adjusted BMI.

\begin{tabular}{|c|c|c|c|c|c|c|c|c|}
\hline variable & $M(S D)$ & $B$ & $S E B$ & $\beta$ & $t$ & $F$ & $95 \% \mathrm{CI}$ & $R^{2}$ change \\
\hline Step 1 & & & & & & $35.48^{* *}$ & & \\
\hline Age (year) & $17.24(4.83)$ & -13.76 & 2.31 & -.43 & $-5.96 * *$ & & {$[-18.32--9.20]$} & $.18^{* *}$ \\
\hline Step 2 & & & & & & $20.70 * *$ & & \\
\hline Age (year) & & -14.08 & 2.29 & -.44 & $-6.16^{* *}$ & & {$[-18.59--9.56]$} & \\
\hline Mean $\mathrm{AB}$ scores (ms) & $3.52(22.36)$ & -5.12 & 2.29 & -.16 & $-2.24 *$ & & {$[-9.64--0.61]$} & $.03^{*}$ \\
\hline Step 3 & & & & & & $16.74 * *$ & & \\
\hline Age (year) & & -12.44 & 2.32 & -.39 & $-5.35^{* *}$ & & {$[-17.03--7.85]$} & \\
\hline Mean AB scores (ms) & & -4.80 & 2.25 & -.15 & $-2.14 *$ & & {$[-9.24--0.37]$} & \\
\hline Variability of RT on filler trials & $0.16(0.04)$ & 6.23 & 2.32 & .19 & $2.68^{* *}$ & & {$[1.64-10.81]$} & $.04 * *$ \\
\hline Step 4 & & & & & & $15.39 * *$ & & \\
\hline Age (year) & & -9.37 & 2.49 & -.29 & $-3.76^{* *}$ & & {$[-14.29--4.44]$} & \\
\hline Mean AB scores (ms) & & -5.02 & 2.19 & -.16 & $-2.29 *$ & & {$[-9.35--0.69]$} & \\
\hline Variability of RT on filler trials & & -0.00 & 3.09 & .00 & -0.00 & & {$[-6.10-6.09]$} & \\
\hline TL-BS variability (ms) & $105.75(48.04)$ & 10.02 & 3.37 & .31 & $2.97^{* *}$ & & [3.36-16.67] & $.04 * *$ \\
\hline
\end{tabular}

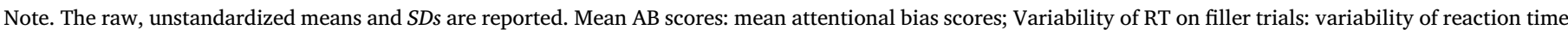

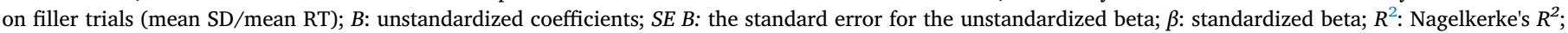
${ }^{*} p<.05 ; * * p<.01$.

linear regressions, the model including only standardized mean $\mathrm{AB}$ scores significantly explained variance in BMI after controlling for age. Introducing the variability of RT on filler trials significantly improved the model. Finally, adding the standardized TL-BS variability in the last step explained an additional $4.1 \%$ of the variation in BMI and this change in $R^{2}$ was significant. See Table 4.

According to the results of meta-analysis, we can conclude that there was a significant associated between TL-BS variability and adjusted BMI $\%$, and such associations also exist in the variability of RT on filler trials. However, TL-BS variability for food was the best predictor of adjusted $\mathrm{BMI} \%$ and could significantly explain variance in \% BMI after controlling for age, mean AB and variability of RT on filler trials. Again, TL-BS was not related to variability in dwell time, which suggests that TL-BS might not reflect attention towards and away from food.

\section{General discussion}

Previous research on food-related $\mathrm{AB}$ did not produce consistent results (e.g., Roefs et al., 2015; Werthmann et al., 2015). Recently, several studies used a new computational method, TL-BS, to calculate variability of the attentional bias (AB) data in emotion-related dotprobe tasks and produced more consistent results (Zvielli et al., 2015, 2016). However, this TL-BS approach has not been taken yet in research on biased attention for food.

In the current paper, we used this novel computational method to reanalyze $\mathrm{AB}$ data in three different groups, overweight/obese adults, obese children, and normal-weight restrained eaters, all compared to control groups. We also chose the variability of RT on filler trials (mean $\mathrm{SD} /$ mean $\mathrm{RT}$ ) to measure the variability on general responding. The main findings were (1) Overall, people with higher BMI demonstrated larger TL-BS variability for food (study 1, 2 and meta-analysis). (2) When controlling for the variability of RT on filler trials and mean $\mathrm{AB}$ scores, TL-BS variability could still significantly predict the variance in BMI (study 2 and meta-analysis, although not in study 1). (3) Both overweight/obese adults and obese children demonstrated larger variability of RT on filler trials (study 1, 2 and meta-analysis). (4) The variability of attentional bias for food (TL-BS variability) was not correlated significantly with dwell time variability and restrained eating scores (all studies).

From all the studies, we can conclude that overweight/obese women and obese children all are characterized by higher variability of reaction time based attentional bias for food and general responding. The variability of food-related attentional bias and general responding may due to the executive control ability, as overweight/obese people showed impairments of executive function (Yang, Shields, Guo, \& Liu,
2018). The relation between restrained eating and executive functioning is less clear, with inconsistent results in the literature (Meule, Lukito, Vögele, \& Kübler, 2011; Nederkoorn, Van Eijs, \& Jansen, 2004) and together with the present results this might suggest that restrained eating is not related to diminished executive functioning. However, some research suggested that executive functioning might be specifically related to uncontrolled eating or unsuccessful dietary restrained and not to restrained eating in general (Martin, Davidson, \& McCrory, 2018; Van Koningsbrugge, Stroebe \& Aarts, 2013). In future research, it should be tested if unsuccessful dieting, instead of general restrained, is related to increased variability in food-related attentional bias or to general responding.

The results of study 2 and meta-analysis showed that the variability of $\mathrm{AB}$ for food (TL-BS variability) could predict additional variance of BMI above the variability of general responding. It demonstrates the necessity to consider the role of time when measuring reaction time based attentional bias for food and merely focus on the aggregated mean scores cannot draw the whole picture of attentional bias for food. It also provides us with the evidence that people with higher BMI may have more approach-avoidance towards food. However, the reanalyzes all revealed that dwell time variability was not correlated with TL-BS variability. Dwell time is defined as the maintenance of attention on critical stimuli (Mogg et al., 2005). The bigger dwell time represents participants lingering longer on critical stimuli (towards target) and vice versa. It seems therefore reasonable to consider that TL-BS variability may not link to attention towards or away from food. Hence, it is difficult to indicate what the variability of attentional bias for food (TLBS variability) reflects in our current paper. More research is needed in which TL-BS is validated, for instance by relating it to more other measures of goal conflict. The underlying mechanism on the variability of attentional bias is unclear, but these results do show TL-BS can predict the variance in BMI, so this new direction is interesting.

Several limitations should be mentioned. First, TL-BS variability can only capture the degree of fluctuation, but it cannot provide us with the frequency of bias switches, which is also a critical index to weigh the dynamic changes of $\mathrm{AB}$. It still needs great efforts to develop a better method to capture the dynamic nature of AB. Second, our participants in study 1 and study 3 only included female participants, so the results cannot be generalized to males.

In summary, the present findings show that the variability of attention in both obese/overweight women and children is not specific for food stimuli but is also apparent for non-food stimuli, whereas the larger variability of $\mathrm{AB}$ for food seems to characterize obese people, especially in obese children, better than the variability of general responding. The variability of $\mathrm{AB}$ for food showed no significant 
correlation with dwell time variability and restrained eating scores. These findings suggested that TL-BS can partly predict the variance in BMI, but it is not clear what it actually reflects, casting doubt on the validity of the measure. More research is needed to test the relation between general attention, attention for food, food intake, and overweight/obesity.

\section{Declaration of conflicting interests}

None.

\section{Acknowledgments}

The authors would like to thank Ariel Zvielli for providing the codes and instruction of trial-level bias score (TL-BS) approach.

\section{Appendix A. Supplementary data}

Supplementary data to this article can be found online at https:// doi.org/10.1016/j.appet.2019.01.004.

\section{References}

Ataya, A. F., Adams, S., Mullings, E., Cooper, R. M., Attwood, A. S., \& Munafò, M. R (2012). Internal reliability of measures of substance-related cognitive bias. Drug and Alcohol Dependence, 121(1-2), 148-151. https://doi.org/10.1016/j.drugalcdep.2011. 08.023.

Bardeen, J. R., Daniel, T. A., Hinnant, J. B., \& Orcutt, H. K. (2017). Emotion dysregulation and threat-related attention bias variability. Motivation and Emotion, 41(3), 402-409. https://doi.org/10.1007/s11031-017-9604-z.

Berridge, K. C., Ho, C. Y., Richard, J. M., \& DiFeliceantonio, A. G. (2010). The tempted brain eats: Pleasure and desire circuits in obesity and eating disorders. Brain Research, 1350, 43-64. https://doi.org/10.1016/j.brainres.2010.04.003.

Deluchi, M., Costa, F. S., Friedman, R., Goncalves, R., \& Bizarro, L. (2017). Attentional bias to unhealthy food in individuals with severe obesity and binge eating. Appetite, 108, 471-476. https://doi.org/10.1016/j.appet.2016.11.012.

Doolan, K. J., Breslin, G., Hanna, D., \& Gallagher, A. M. (2015). Attentional bias to foodrelated visual cues: Is there a role in obesity? Proceedings of the Nutrition Society, 74(1), 37-45. https://doi.org/10.1017/S002966511400144X.

Field, M., Werthmann, J., Franken, I., Hofmann, W., Hogarth, L., \& Roefs, A. (2016). The role of attentional bias in obesity and addiction. Health Psychology, 35(8), 767-780. https://doi.org/10.1037/hea0000405.

Frankort, A., Roefs, A., Siep, N., Roebroeck, A., Havermans, R., \& Jansen, A. (2012). Reward activity in satiated overweight women is decreased during unbiased viewing but increased when imagining taste: An event-related fMRI study. International Journal of Obesity, 36(5), 627-637. https://doi.org/10.1038/ijo.2011.213.

Herman, C. P., \& Polivy, J. (1980). Restrained eating. In A. J. Stunkard (Ed.). Obesity (pp. 209-224). Philadelphia: Saunders.

Kruijt, A. W., Field, A. P., \& Fox, E. (2016). Capturing dynamics of biased attention: Are new attention variability measures the way forward? PLoS One, 11(11), e0166600. https://doi.org/10.1371/journal.pone.0166600.

Lake, A., \& Townshend, T. (2006). Obesogenic environments: Exploring the built and food environments. Journal of the Royal Society for the Promotion of Health, the, 126(6), 262-267. https://doi.org/10.1177/1466424006070487.

MacLeod, C., Mathews, A., \& Tata, P. (1986). Attentional bias in emotional disorders. Journal of Abnormal Psychology, 95(1), 15-20. https://doi.org/10.1037/0021-843x. 95.1.15.

Martin, A. A., Davidson, T. L., \& McCrory, M. A. (2018). Deficits in episodic memory are related to uncontrolled eating in a sample of healthy adults. Appetite, 124, 33-42. https://doi.org/10.1016/j.appet.2017.05.011.

McSorley, E., Morriss, J., \& van Reekum, C. M. (2017). Eye spy with my little eye: Motivational relevance of visual stimuli guide eye-movements at different processing stages. Biological Psychology, 123, 8-14. https://doi.org/10.1016/j.biopsycho.2016. 11.008 .

Meule, A., Lukito, S., Vögele, C., \& Kübler, A. (2011). Enhanced behavioral inhibition in restrained eaters. Eating Behaviors, 12(2), 152-155. https://doi.org/10.1016/j. eatbeh.2011.01.006.

Mogg, K., Field, M., \& Bradley, B. P. (2005). Attentional and approach biases for smoking cues in smokers: An investigation of competing theoretical views of addiction. Psychopharmacology, 180(2), 333-341. https://doi.org/10.1007/s00213-005-2158-x.

Nederkoorn, C., Van Eijs, Y., \& Jansen, A. (2004). Restrained eaters act on impulse. Personality and Individual Differences, 37(8), 1651-1658. https://doi.org/10.1016/j. paid.2004.02.020.

Nijs, I. M., Franken, I. H., \& Muris, P. (2010). Food-related Stroop interference in obese and normal-weight individuals: Behavioral and electrophysiological indices. Eating Behaviors, 11(4), 258-265. https://doi.org/10.1016/j.eatbeh.2010.07.002.

Nummenmaa, L., Hietanen, J. K., Calvo, M. G., \& Hyona, J. (2011). Food catches the eye but not for everyone: A BMI-contingent attentional bias in rapid detection of nutriments. PLoS One, 6(5), e19215. https://doi.org/10.1371/journal.pone.0019215.

Roefs, A., Houben, K., \& Werthmann, J. (2015). Desire for food and the power of mind. In W. Hofmann, \& L. F. Nordgren (Eds.). The psychology of desire (pp. 323-346). New York, NY: Guilford Press.

Schmukle, S. C. (2005). Unreliability of the dot probe task. European Journal of Personality: Published for the European Association of Personality Psychology, 19(7), 595-605. https://doi.org/10.1002/per.554.

Stroebe, W., van Koningsbruggen, G. M., Papies, E. K., \& Aarts, H. (2013). Why most dieters fail but some succeed: A goal conflict model of eating behavior. Psychological Review, 120(1), 110-138. https://doi.org/10.1037/a0030849.

Van Koningsbruggen, G. M., Stroebe, W., \& Aarts, H. (2013). Successful restrained eating and trait impulsiveness. Appetite, 60, 81-84. https://doi.org/10.1016/j.appet.2012. 09.016.

Van Winckel, M., \& Van Mil, E. (2001). Wanneer is dik te dik? In C. Braet, \& M. Van Winckel (Eds.). Behandelingsstrategieen bij kinderen met overgewicht (pp. 11-26). Houten, the Netherlands: Bohn Stafleu Van Loghum.

Werthmann, J., Jansen, A., \& Roefs, A. (2015). Worry or craving? A selective review of evidence for food-related attention biases in obese individuals, eating-disorder patients, restrained eaters and healthy samples. Proceedings of the Nutrition Society, 74(2), 99-114. https://doi.org/10.1017/S0029665114001451.

Werthmann, J., Jansen, A., \& Roefs, A. (2016). Make up your mind about food: A healthy mindset attenuates attention for high-calorie food in restrained eaters. Appetite, 105, 53-59. https://doi.org/10.1016/j.appet.2016.05.005.

Werthmann, J., Jansen, A., Vreugdenhil, A. C. E., Nederkoorn, C., Schyns, G., \& Roefs, A. (2015). Food through the child's eye: An eye-tracking study on attentional bias for food in healthy-weight children and children with obesity. Health Psychology, 34(12), 1123-1132. https://doi.org/10.1037/hea0000225.

Werthmann, J., Roefs, A., Nederkoorn, C., Mogg, K., Bradley, B. P., \& Jansen, A. (2011). Can(not) take my eyes off it: Attention bias for food in overweight participants. Health Psychology, 30(5), 561-569. https://doi.org/10.1037/a0024291.

Werthmann, J., Roefs, A., Nederkoorn, C., Mogg, K., Bradley, B. P., \& Jansen, A. (2013) Attention bias for food is independent of restraint in healthy weight individuals-an eye tracking study. Eating Behaviors, 14(3), 397-400. https://doi.org/10.1016/j. eatbeh.2013.06.005.

Wilcox, R. R. (2001). Fundamentals of modern statistical methods: Substantially improving Power and accuracy. New York: Springer.

Yang, Y., Shields, G. S., Guo, C., \& Liu, Y. (2018). Executive function performance in obesity and overweight individuals: A meta-analysis and review. Neuroscience \& Biobehavioral Reviews, 84, 225-244. https://doi.org/10.1016/j.neubiorev.2017.11. 020

Zvielli, A., Bernstein, A., \& Koster, E. H. (2015). Temporal dynamics of attentional bias. Clinical Psychological Science, 3(5), 772-788. https://doi.org/10.1177/ 2167702614551572.

Zvielli, A., Vrijsen, J. N., Koster, E. H., \& Bernstein, A. (2016). Attentional bias temporal dynamics in remitted depression. Journal of Abnormal Psychology, 125(6), 768-776. https://doi.org/10.1037/abn0000190. 